\title{
ANÁLISE DA PERCEPÇÃO DOS PROFESSORES DE EDUCAÇÃO FÍSICA ACERCA DA INTERFACE ENTRE A SAÚDE E A EDUCAÇÃO FÍSICA ESCOLAR: CONCEITOS E METODOLOGIAS
}

\author{
DR. HERALDO SIMÕES FERREIRA \\ Curso de Educação Física e Programa de Pós-graduação em Educação, \\ Universidade Estadual do Ceará (UECE) (Fortaleza - Ceará - Brasil) \\ E-mail: heraldosimoes@bol.com.br
}

\section{ESP. BRAULIO NOGUEIRA DE OLIVEIRA}

Escola de Formação Profissional em Saúde da Família Visconde de Sabóia,Ministério da Saúde (Sobral - Ceará - Brasil)

E-mail: brauliono08@hotmail.com

\author{
DR. JOSÉ JACKSON COELHO SAMPAIO \\ Departamento de Saúde Pública, Universidade \\ Estadual do Ceará (Fortaleza - Ceará - Brasil) \\ E-mail: sampaiojackson@gmail.com
}

\begin{abstract}
RESUMO
O presente estudo visa analisar a percepção dos professores de Educação Física da rede municipal de ensino de Fortaleza-CE, acerca de sua concepção de saúde e da relação desta com a Educação Física escolar. Trata-se de um estudo qualitativo, analítico-crítico, em que se utilizou o método da análise de conteúdo. Nessa feita, foram realizadas entrevistas com nove professores, sendo elencadas as seguintes categorias analíticas: motivos da utilização do tema saúde nas aulas; relação atividade fisica e saúde; e metodologias de ensino. Conclui-se que, de modo geral, o conceito de saúde adotado não contempla o seu sentido ampliado, dessa forma, torna-se necessário ultrapassar os aspectos individuais e biológicos de suas práticas.
\end{abstract}

PALAVRAS-CHAVE: Educação Física; escola; saúde pública; recursos humanos. 
Na Educação Física, o modelo biomédico, no que se refere ao entendimento de saúde, ainda repercute fortemente, que por sua vez, considera o paradigma cartesiano como diretriz. Elimina as dúvidas, compreende o todo a partir de suas partes, respeita a hierarquia dos saberes, enumera para replicar e valoriza a mente em detrimento da matéria (ROCHA; CENTURIÃO, 2007; LUZ, 2007). Entretanto, tal realidade está em processo de alteração, e novos debates, discussões e compreensões tendem a surgir no campo científico da área. Não se despreza a relevância de tais conceitos, no entanto, torna-se necessário que sejam considerados aspectos psicossociais inerentes ao bem estar geral do sujeito.

Ainda é possível observar cursos de formação de professores de Educação Física centrados na melhoria da aptidão física e preocupados somente com a aprendizagem de gestos e técnicas motoras, em detrimento do estímulo à reflexão. Se encontram pautados na visão reducionista da Educação Física, implementando a defesa do esporte e da saúde individual (BAGRICHEVSKY, 2007).

O ambiente educacional possui os requisitos necessários para ser o momento de partida na busca pelo conhecimento em saúde, entre outras maneiras, através de ações de educação e promoção da saúde. Desse modo, a escola, apoiada pela família e pelas políticas públicas, deveria ser o primeiro contato das crianças com a compreensão de saúde, tendo em vista que possui a Educação Física Escolar (EFE) enquanto componente curricular obrigatório em todo o ensino básico (BRASIL, 2000a). Nesse sentido, Gerber (1992) e Maitino (1998) afirmam que ao educar crianças para a saúde estaremos produzindo futuros adultos saudáveis. Desta forma, compreendemos que a EFE, por ser um componente da área da saúde e figurar obrigatoriamente no corpo de disciplinas da escola, se impõe como um poderoso meio para promoção da saúde.

Sabe-se que os Parâmetros Curriculares Nacionais (BRASIL, 1998) buscam atrelar-se a um conceito de saúde que supere o paradigma biológico e informativo. No documento são considerados os diversos enfoques que formam a composição do cenário da saúde, incluindo aí os aspectos sociais, econômicos, culturais, afetivos e psicológicos. Em seu texto introdutório, tais Parâmetros apresentam o desafio de educar para a saúde, no que se refere a hábitos e atitudes de vida (BRASIL, 2000b).

Possivelmente, a transmissão de conhecimento de saúde nas escolas brasileiras, quando efetivada, tem se realizado através de meras informações sobre os aspectos biológicos do corpo, a descrição de doenças e suas causas e de hábitos e de higiene. Estas situações não são resolutivas para que os alunos desenvolvam atitudes de vida saudável (BRASIL, 1998). 
Peregrino (2000) reforça a ideia do ensino de saúde errôneo na educação do Brasil. De acordo com a autora, o ensino é linear e tradicional, segue uma complexidade crescente, mas fragmentada, não há uma relação dos assuntos de saúde com o contexto social e cultural dos alunos.

De acordo com Miranda (2006), a Educação Física não tem sido efetivamente resolutiva quando se pensa em proporcionar conhecimento sobre saúde aos escolares. Concordando, Sleap (1990) afirma que a disciplina Educação Física não pode estagnar na representação de uma educação do corpo, deve avançar para a compreensão de uma educação para o corpo, contemplando demandas relacionadas aos determinantes sociais e suas implicações. Marques et al. (20।2), ao descrever as percepções dos adolescentes sobre saúde e cuidado, identificaram concepções voltadas à atitude pessoal, associada ao exercício físico, a uma boa alimentação e a um bom convívio social.

Silva (20 I I ) evidencia a tematização do discurso da mídia sobre a saúde com alunos do ensino médio. Segundo a autora, informações inerentes à mídia televisiva produzem uma visão de saúde e atividade física atrelada à necessidade de fuga do sedentarismo, de se movimentar e ser ativo. Tais informações repercutem na legitimidade do saber médico, pelos discursos que controlam o corpo e a implicação para Educação Física.

Diante do exposto, o presente estudo visa analisar a percepção dos professores de Educação Física da rede municipal de ensino de Fortaleza/CE, acerca de sua concepção de saúde e da relação desta com a EFE, entendendo como eles desenvolvem e aplicam essa temática em suas aulas e, a partir daí, refletir acerca de como se dá o pensamento dominante na área em relação à saúde enquanto conteúdo.

\section{METODOLOGIA}

Trata-se de um estudo qualitativo, analítico-crítico. A escolha pelo estudo de natureza analítica deveu-se à busca de uma compreensão do problema proposto e passível de questionamentos. O presente estudo também é crítico, já que utilizará o discernimento criterioso, em contextos históricos bem demarcados, aceitando ou discordando de ideias formuladas pelo conhecimento humano, recorrendo-se, então, à lógica dialética.

A abordagem da dialética compreende os fatos e as quantidades como faces dos fenômenos, não expressão fiel ou totalidade (MINAYO, 1994). A compreensão e a relação com o todo, buscando a interiorização e exteriorização como constituintes do fenômeno social, que deve ser entendido nas suas determinações e transformações dadas pelos sujeitos, são objetivos do estudo crítico.

O cenário da pesquisa foi representado por seis escolas públicas municipais de Fortaleza. Foi escolhida propositalmente a escola com o maior número de alunos 
matriculados de cada Secretaria Executiva Regional (SER). Em $1^{\circ}$ de janeiro de 1997, foi aprovada a Lei Municipal n 8.000, por meio da qual a cidade de Fortaleza ganha uma estrutura organizacional baseada em seis SER (FORTALEZA, 2008).

Oniverso da pesquisa foi constituído pelo número de professores lotados nas escolas da rede municipal de ensino. A população foi composta pelos professores de Educação Física das escolas municipais. A amostra resumiu-se à soma de todos os professores que lecionavam a disciplina EFE nas escolas participantes do estudo, totalizando, na proposta inicial, 18 docentes, posteriormente alterada para número (n) igual a nove, já que foi incluída na proposta a possibilidade de parar as entrevistas quando as respostas passassem a apresentar saturação. Uma grande lógica da pesquisa qualitativa pode ser traduzida pela formulação de critérios para fase posterior, ao final das principais análises referentes à fase anterior.

critério final de inclusão dos professores englobou aqueles que estavam, no momento da pesquisa, lecionando a disciplina EFE nas escolas selecionadas e que assinaram o Termo de Consentimento Livre e Esclarecido (TCLE).

Como critério de exclusão, foi utilizado o fato de o professor não possuir graduação completa em Educação Física, de tal forma que foram excluídos da pesquisa estagiários e outros docentes que porventura estavam assumindo a disciplina em questão, porém não graduados na área.

Iniciou-se a coleta de dados empíricos após a realização de uma revisão sistemática através de estudo específico na literatura. Foram utilizadas as bases de dados Medline, Lilacs e Scielo, sendo priorizados os estudos publicados nos últimos cinco anos.

Para o processo de coleta de dados foi utilizada a entrevista estruturada com os professores. Nesta fase, pretendeu-se verificar os conhecimentos dos professores envolvidos no estudo sobre aspectos conceituais de saúde acerca de como aplicavam o tema em suas aulas. A aplicação da entrevista seguiu o mesmo padrão metodológico em todas as escolas. Os docentes marcavam dia e horário para a entrevista e esta era realizada na sala dos professores da escola. A entrevista ocorria somente com a presença do participante e do entrevistador, e durava em média 20 minutos.

A análise dos dados obtidos pelas entrevistas foi realizada por meio da interpretação das falas dos atores envolvidos. Para tanto foi utilizada a análise de conteúdo (MINAYO, 2003). Assim sendo, a análise teve como finalidade verificar hipóteses e ou descobrir o que estava emergindo de cada conteúdo manifesto pelos envolvidos na pesquisa.

Para a realização da pesquisa, foram respeitadas as normas éticas que regem a pesquisa científica com seres humanos, conforme Resolução no 196/96, da Comissão 
Nacional de Ética em Pesquisa do Conselho Nacional de Saúde. Conforme o parecer número Processo n $10030697-7$, folha de rosto n 3243 I7, o projeto de pesquisa foi aprovado pelo Comitê de Ética em Pesquisa da Universidade Estadual do Ceará.

\section{CONCEPÇÕES ACERCA DA SAÚDE NA EDUCAÇÃO FÍSICA ESCOLAR}

Decerto, as concepções inerentes à atuação profissional possuem influências de seu processo formativo. Luz (2007), ao comentar a formação professor de Educação Física, alerta sobre a relação com campo biomédico, na grande área da saúde, permeada por disciplinas como fisiologia e anatomia, direcionada pelo quadro epistemológico biomecânico moderno e herdeira de práticas ligadas ao treinamento e adestramento do corpo.

Maitino ( 1998) enfatiza que a EFE, por estudar o movimento humano, pode proporcionar conhecimento aos alunos no que se refere à manutenção e aquisição de saúde. Além disso, os PCNs, inspirados nos textos e nas obras de Canguilhem, idealizam o preenchimento desta lacuna no ensino de saúde. Buscam um modelo de compreensão de saúde mais abrangente, não excluem as questões biológicas, mas defendem os determinantes sociais como sendo um divisor de águas do entendimento de saúde (BRASIL, 2000b). Compreende-se que esta é a abordagem mais próxima dos ideais da saúde coletiva, por considerar fatores externos, e não somente a prática de exercícios, como indicadores de saúde, incluindo características extremamente importantes no campo da própria saúde coletiva, como a humanização, o cuidado consigo e com o outro, o vínculo e o diálogo.

As respostas para este estudo revelam que todos os participantes da pesquisa usam o tema saúde em suas aulas. Na verdade, as diferenças se apresentavam nos motivos e metodologias. A partir das respostas emergentes, foram elencadas três categorias analíticas: motivos da utilização do tema saúde nas aulas, elucidando a conceituação estruturante para o seu uso; relação atividade física e saúde, visto relativo direcionamento por grande parte dos entrevistados; e metodologias de ensino, que permeiam entre as aulas teóricas e práticas.

A possibilidade de desenvolvimento da psicomotricidade e da emancipação crítica favorece a Educação Física a proporcionar o entendimento de saúde aos escolares. Miranda (2006) sustenta que as curiosidades dos alunos com o próprio corpo e a descoberta das possibilidades corporais favorecem a receptividade às informações de saúde. Para Sleap (1990), a EFE é o melhor local para a promoção e a educação em saúde. Desse modo, é difícil imaginar que os objetivos da disciplina não sejam senão os de favorecer o conhecimento de saúde (SLEAP, 1990). A seguir se apresentam alguns motivos citados pelos professores para adoção da temática em suas aulas: 
"(...) porque é um tema que é interessante ser desenvolvido a todo o momento pelos alunos (...) então quanto puder falar desses aspectos da saúde, direcionada a aquisição de capacidades físicas ou até mesmo relacionada à saúde mental e espiritual, o conceito de saúde estará sendo trabalhado." (SER II, Prof. I)

Saúde nos dias atuais é um conceito bem mais amplo do que somente ausência de doença, passa por um bem estar, não só físico, não só orgânico como também um bem estar social se não tem garantia de condições de moradia, acesso a saúde como um bem a pessoa pode considerar ter saúde. Eu entendo saúde não só como a questão da doença, mais a questão de bem estar geral. (SER IV, Prof. I).

As falas supracitadas, embora se restrinjam a poucos professores, elucidam relativa consonância da utilização do tema com determinadas propostas da Saúde Coletiva ao abordar temas favoráveis à saúde, para além da atividade física.

De acordo com a LDB (BRASIL, 2000a), a Educação Física, integrada à proposta pedagógica da escola, é componente curricular obrigatório na Educação Básica, ajustando-se às faixas etárias e às condições da população escolar de modo a contribuir para o desenvolvimento do organismo e da personalidade do educando. Assim, observa-se nas falas acima que os professores de Educação Física, resguardando seu direito de liberdade de planejamento, podem fazer valer sua formação na saúde, e recorrer a temas que subsidiem ações de educação em saúde nos ambientes de ensino, tais como a saúde mental e espiritual e os determinantes sociais.

Nos motivos citados a seguir, o pensamento da relação causal entre 'atividade física/aquisição da saúde' permeiam aos discursos dos professores, sendo essa mais uma categoria analítica, como se compreende nas falas:

"(...) porque eu acho relevante que os alunos entendam a importância do exercício que está
sendo executado, principalmente porque a Educação Física proporciona ao aluno uma melhor
condição de vida e de saúde, dependendo da forma como ela for executada" (SER I, Prof. 2)
"O objetivo de mostrar o bem-estar pra realização de suas atividades. Se o aluno estiver bem
consigo, com os outros, mentalmente e na sua condição física ele está bem com a saúde.
Eu digo até pra eles que a atividade física, alimentação adequada e um bom descanso é igual
à saúde. Considero a fórmula básica para ter uma boa qualidade de vida" (SER III, Prof. I)

As falas citadas trazem elementos relevantes no processo saúde/doença/ cuidado, elucidando elementos pertinentes ao bem estar, como o exercício físico, alimentação e descanso adequados. Todavia, é preciso ser considerado os determinantes sociais nesse processo, tais como a moradia, o saneamento básico, o meio ambiente, o trabalho, a renda, a educação, o transporte, o lazer e o acesso aos bens e serviços essenciais; além do entendimento que a organização social e econômica do País possui relevante implicação com a saúde (BRASIL, 1990). 
Autores como Guedes e Guedes ( 1993 ) defendem a proposta de que a EFE necessita, em sua proposta pedagógica, se direcionar à educação e à promoção da saúde. Neste sentido, a disciplina deve superar suas raízes técnicas e biológicas, voltadas unicamente para desenvolvimento de habilidades esportivas e atléticas, e incluir em seus conteúdos o tema saúde.

Corroboramos com Palma (200 I ), ao considerar que a saúde não pode ser adquirida somente com a prática da atividade física, e, além disso, esta prática pode não resultar necessariamente em saúde. Parâmetros e informações socioeconômicos e culturais podem influenciar nesse processo.

A teoria de Guedes e Guedes (1993), denominada de Saúde Renovada por Darido e Rangel (2005), possui excelentes colaborações para com a Educação Física, como o combate ao esportivismo e ao tecnicismo, a diretriz aos professores em favorecer o conhecimento sobre atividade física e o posicionamento final de estimular a uma vida ativa, mesmo após a idade escolar. Entretanto, ao pensar a saúde na perspectiva coletiva, com todos os seus fatores sociais, vislumbra-se a falta de debates, na teoria dos autores, sobre condições de alimentação, habitação, educação, renda, meio ambiente, trabalho, transporte, emprego, lazer, liberdade, acesso e posse da terra e acesso aos serviços de saúde.

Assim, não é de se estranhar que a Educação Física, em enorme parcela de seu universo, compreenda a saúde apenas como sinônimo de práticas de exercícios corporais (GÓIS JÚNIOR; LOVISOLO, 2003). Costa e Venâncio (2004) compreendem que uma parte dos professores de Educação Física despreza o posicionamento crítico e ético sobre saúde e promove atividades físicas apenas com o intuito de transformar o corpo em um ideal atlético para corresponder a apelos da mídia.

Rocha e Centurião (2007) completam seu pensamento e citam que devemos considerar a questão saúde para além de questões orgânicas; as questões sociais devem ser consideradas, para isso, o profissional da área da saúde deve ampliar seus horizontes e adquirir outros saberes que não somente os da área biomédica.

Bagrichevsky (2007) também critica a relação atividade física - saúde como única preocupação da Educação Física. $\bigcirc$ autor cita que, durante o início da década de 80, discutir aptidão física significava preocupar-se com saúde. Afirma que nenhum autor se preocupou em questionar as dimensões individualistas e a preocupação única da área com o paradigma atividade física - saúde. Para o autor, houve um conformismo sobre o aspecto biológico da saúde na Educação Física. Os aspectos de saúde extra-atividade física, como significado resultante das condições de vida oferecidas pelo Estado, foram excluídos dos debates acadêmicos na Educação Física.

Outros autores demonstram preocupação com o axioma inquestionável da Educação Física: atividade física é saúde. Ceccin e Bilibio (2007) relatam que a Educação Física foi considerada positivista pela relação de causa e efeito entre exercício 
físico e saúde, onde a falta da atividade física é considerada a causa de doenças e sua aplicação à restauração da saúde. Para os autores, a Educação Física não deve possuir como objeto a cura ou a aptidão física, mas a produção do cuidado para com a vida em sua expressão corporal. E é na escola que a Educação Física se legitima como um meio efetivo para a educação em saúde.

Se o conteúdo está manifesto, emerge outra categoria analítica: Que metodologia de ensino está sendo usada pelos professores, para abordar o tema da saúde? Os resultados apontam aulas teóricas, práticas e teórico-práticas enquanto método. As falas a seguir apresentam a postura de alguns dos envolvidos:

\footnotetext{
“Trabalhamos o tema saúde em aulas teóricas (...) desse modo, a proposta pedagógica é justamente ensinar para cada um deles a importância daquele exercício e a finalidade, o objetivo que iremos atingir levando em conta a saúde, a postura, a respiração, coisas desse tipo (...)" (SER I, Prof. 2)

"Eu utilizo mais nas aulas teóricas, associando e mostrando pra eles que pra ter uma boa prática eles têm que ter uma boa saúde." (SER III, Prof. I).

"Eu trabalho a saúde com informações, nesse bimestre a gente está realizando um trabalho sobre alimentação, recortando rótulos, aprendendo um pouco sobre informações nutricionais; em outro bimestre falamos sobre higiene pessoal. Nas aulas práticas, temos dificuldades por não termos quadro nem espaço, aí nos adaptamos alguma coisa em sala mesmo, texto, alguma coisa assim." (SER IV, Prof. I).
}

Nas falas citadas percebe-se que a aula teórica é considerada por grande parcela dos pesquisados o único caminho para tratar o tema nas sessões de Educação Física, pois, acreditam que a aula prática não é o local ideal para a aplicação do tema saúde.

No entanto, existem professores que enfrentam muitas dificuldades em trabalhar aulas teóricas, tornando-as muitas vezes escassas. Zimbres (200 I) demonstra à afirmativa e explica que os principais motivos são: os conhecimentos teóricos são relacionados aos interesses dos professores e não direcionados aos interesses dos alunos; tanto professores como alunos compreendem que as aulas teóricas devem ter como ambiente exclusivo a sala de aula ou qualquer outro ambiente fechado; grande parte dos professores não possui embasamento teórico e domínio de técnicas criativas para transmitir os conteúdos aos alunos, independentemente do cenário; muitos professores se mantêm reféns da concepção de que teoria é metafísica, especulação, perda de tempo nas aulas.

Todavia, como pode ser notado nas falas dos entrevistados, essa realidade vem mudando, elucidando relativa clareza quanto à preferência pelas aulas teóricas, 
ao menos ao se desenvolver o tema saúde. Além dessa, outras metodologias vêm sendo adotadas, que podem ser reveladas nas seguintes respostas:

\footnotetext{
"Ministro o tema saúde em aulas teóricas com trabalhos e pesquisas. Além disso, desenvolvo principalmente a prática, na questão de alongamento, postura, na importância da atividade física." (SER I, Prof. I)

“(...) de forma indireta dependendo da série o tema saúde é desenvolvido de forma bem diversificada. Para alunos da primeira á quarta série, trabalho o tema de forma mais recreativa (...) geralmente eu abordo na própria aula prática (...)." (SER VI, Prof. I)
}

Cabe aqui uma pequena digressão sobre as aulas teóricas na Educação Física. Há escolas em que a proposta pedagógica da disciplina para se trabalhar a temática saúde é somente de forma prática; outras em que existem aulas distintas, teóricas e práticas; e ainda há aquelas em que a teoria divide espaço com momentos práticos.

Barbosa (1997), em seus estudos sobre teoria e prática, defende que o processo interno e abstrato, o pensamento, é adquirido na teoria e, por sua vez, o ato concreto de sentir, ver, ouvir e sentir o conteúdo da aprendizagem só é transmitido pela prática. Afirma ainda que é na aula prática que os conteúdos das aulas teóricas são inseridos na práxis dos alunos, através da realização do gesto motor imbuído de cultura corporal, proporcionando uma significação ao simples gesto técnico do movimentar.

Corroboramos com Mattos e Neira (2000) ao postular que as aulas podem ser divididas em dois momentos: segmento teórico e segmento prático. Para estes autores, a parte teórica objetiva a compreensão de conceitos e a parte prática objetiva vivenciarem o que foi assimilado na teoria. Dessa forma, é possibilitada uma troca de conhecimento mais efetiva em detrimento de aulas somente teóricas.

O presente estudo identifica a utilização de aulas práticas e teóricas para a transmissão do conceito de saúde. Deduz-se, portanto, que, embora em sua minoria, os docentes entrevistados realizam a ideia de que teoria e prática se completam.

Decerto, a saúde humana é resultante das incorporações individuais das transformações econômicas, sociais e políticas (CARVALHO, 2004). Nesse sentido, a proposta é que, junto com a prática das aulas de EFE, aspectos sociais e da realidade dos alunos também sejam abordados, pois só assim a saúde dos indivíduos poderá ser discutida.

\section{CONSIDERAÇÕES FINAIS}

A partir dos resultados, podemos concluir que o conteúdo Saúde está manifesto na realidade pesquisada, todavia, grande parte dos professores envolvidos 
possui uma percepção restrita de seu significado, sendo direcionada a questões biologicistas. Compreendemos que a Educação Física escolar não deve restringir-se a treinar o corpo, adestrá-lo, ou habilitá-lo. Entende-se que deve ultrapassar estas barreiras, promovendo a saúde enquanto determinada socialmente, baseado no princípio da integralidade.

Partindo do debate como pressuposto teórico, a Educação Física pode se tornar um meio eficaz na aquisição e no conhecimento sobre saúde de seus alunos. Existe uma relação direta entre as tendências da promoção da saúde e da atividade física relacionada à saúde. Nesse sentido, considera-se relevante que se tenha relativo amadurecimento sobre a real função da disciplina no que se refere ao tema saúde, sempre levando em consideração a realidade de seus alunos.

A relação da disciplina escolar com a saúde propõe ultrapassar a barreira de simplesmente praticar atividades físicas. Temáticas como a promoção e proteção à saúde, prevenção de doenças ou agravos de maneira geral, na diagnose, no tratamento, na reabilitação e na manutenção da saúde entre outros, devem ser discutidos, não desprezando os determinantes sociais inerentes ao aluno. Desse modo, sugerimos que o entendimento de saúde, no âmbito escolar, contemple a situação de moradia, acesso à cultura, lazer, empoderamento político, entre outros elementos, para sua compreensão integral. Tais práticas pedagógicas por parte dos professores podem eliciar melhorias para os alunos, além disso, os benefícios mais relevantes seriam voltados para a população em geral, tendo em vista que é possível capacitar os alunos para multiplicação dos saberes.

Compreende-se que a Educação Física está relacionada à compreensão de hábitos saudáveis, discutir, refletir, relacionar e compreender situações coletivas de saúde. Defende-se neste estudo que a Educação Física deve ultrapassar os aspectos individuais e biológicos de suas práticas e partir para um novo rumo coletivo, ou seja, sugere-se que a Educação Física interrompa com os conceitos de saúde tradicionais, dimensionados no individual, e procurar compreender o tema como algo de construção coletiva, rumo à cidadania.

Assim, entende-se que o sentido ampliado do tema saúde, bem como a própria inserção efetiva do conteúdo saúde coletiva no âmbito escolar, possui potencial relevante no sentido de promover novas perspectivas no que se refere a engendrar novas posturas dos professores, ao lidar com essa temática, de maneira que rompa com paradigmas até então dominantes na área. 
Analysis of the Perception of Physical Education Teachers on the Interface Health and Physical Education School: Concepts and Methodologies

ABSTRACT: This study addresses the applicability of the concepts of health in its broadest sense, by the Physical Education teachers in the school in Fortaleza / CE. This is a qualitative study, analytical-critical, where we used the method of Content Analysis. That done, we conducted interviews with nine teachers, and listed the following analytical categories: reasons for using the health issue in classes about physical activity and health, and teaching methodologies. We conclude that in general, teacher's concept of health adopted is not taken into its broad sense, therefore, it is necessary to overcome individual and biological aspects of their practices and for a new direction from the collective.

KEYWORDS: Physical education; public health; school; human resources.

\section{Análisis de la percepción de los profesores de educación física en la relación entre la salud y la educación física en la escuela: conceptos y metodologías}

RESUMEN: Este estudio aborda la aplicabilidad de los conceptos de salud en su sentido más amplio, por los profesores de Educación Física en la escuela en la ciudad de Fortaleza/CE. Se trata de un estudio cualitativo, analítico-crítico, donde se utilizó el método del Análisis del Contenido. Una vez hecho esto, se realizaron entrevistas con nueve profesores, y se enumeran las siguientes categorías de análisis: razones para el uso del tema de salud en las clases sobre la actividad física y salud, y las metodologías de enseñanza. Llegamos a la conclusión de que, en general, el concepto de salud adoptado por los profesores participantes en el estudio no se ocupa de su sentido más amplio, por lo tanto, se hace necesario para superarlos aspectos individuales y biológicos de sus prácticas e ir hacia un nuevo colectivo.

PALABRAS CLAVES: Educación física, salud pública, escuela. recursos humanos.

\section{REFERÊNCIAS}

BAGRICHEVSKY, M. A formação profissional em educação física enseja perspectivas (críticas) para atuação em saúde coletiva?. In: FRAGA, A. B.; WACHS, F. Educação Física e saúde coletiva: políticas de formação e perspectivas de intervenção. Porto Alegre: Ed. da UFRS, 2007.

BARBOSA C. L. Educação Física escolar da alienação à libertação. Petrópolis: Vozes, 1997.

BRASIL. Ministério da Educação. Lei LDB: de diretrizes e bases da educação: lei n. 9.394/96. 3. ed. Brasília: DP\&A, 2000a.

BRASIL. Ministério da Saúde. Lei 8.080: lei orgânica da saúde, de 19 de setembro de 1990. Dispõe sobre as condições para a promoção, proteção e recuperação da saúde, a organização e o funcionamento dos serviços correspondentes e dá outras providências. Brasília, 1990.

BRASIL. Parâmetros Curriculares Nacionais: temas transversais: meio ambiente e saúde. 2. ed. Rio de Janeiro: DP\&A, 2000b. 
BRASIL. Ministério da Educação e Cultura. Secretaria de Educação Fundamental. Parâmetros Curriculares Nacionais: Educação Física. Brasília, 1998.

CARVALHO, Y. M. O "mito" da atividade física e saúde. 4. ed. São Paulo: Hucitec, 2004. 177 p.

CECCIN, R. B.; BILIBIO, L. F. Singularidades da Educação Física na saúde: desafios à educação de seus profissionais e ao matriciamento interprofissional. In: FRAGA, A. B.; WACHS, F. Educação Física e saúde coletiva: políticas de formação e perspectivas de intervenção. Porto Alegre: Ed. da UFRGS, 2007.

COSTA, E. M. B.; VENÂNCIO, S. Atividade física e saúde: discursos que controlam o corpo. Pensar a Prática, Goiânia, v. 7, n. I, p. 59-74, mar. 2004

DARIDO, S. C.; RANGEL. I. C. A. Educação física na escola. Rio de Janeiro: Guanabara Koogan, 2005.

FORTALEZA. Secretaria Municipal de Educação (SME). Censo escolar do município de Fortaleza. Disponível em: <http://www.fme.fortaleza.ce.gov.br/educacao/> . Acesso em: 20 ago. 2008.

GERBER, Z. R. S. Fatores de risco aterosclerótico na infância: estudo epidemiológico. 1992. Dissertação (Mestrado) - Universidade Federal do Rio Grande do Sul, Porto Alegre, 1992.

GÓIS JÚNIOR, E.; LOVISOLO, H. Descontinuidades e continuidades do movimento higienista no Brasil do século XX. Revista Brasileira de Ciências do Esporte, Campinas, v. 25, n. I, p. 4 I-54, set. 2003.

GUEDES, D. P.; GUEDES, J. E. R. P. Subsídios para implementação de programas direcionados à promoção da saúde através da Educação Física Escolar. Revista da APEF, Londrina, v. 8 , n. 15 p. 3-। I, jan. 1993.

LUZ, M. T. Educação Física e saúde coletiva: papel estratégico da área e possibilidades quanto ao ensino na graduação e integração na rede de serviços públicos de saúde. In: FRAGA, A. B.; WACHS, F. Educação Física e saúde coletiva: políticas de formação e perspectivas de intervenção. Porto Alegre: Ed. da UFRGS, 2007.

MAITINO, E. M. Fatores de risco da doença coronária em escolares do ensino básico e suas interfaces com a Educação Física. 1998. Tese (Doutorado) - Faculdade de Filosofia e Ciências, Universidade Estadual Paulista, Marília, 1998.

MARQUES, J. F. et al. Saúde e cuidado na percepção de estudantes adolescentes: contribuições para a prática de enfermagem. Cogitare Enfermagem, v. 17, n. I, p. 37-43, jan./mar. 2012.

MATTOS, M. G.; NEIRA, M. G. Educação Física na adolescência: construindo o conhecimento na escola. São Paulo: Phorte, 2000.

MINAYO, M. C. S. (Org.). Pesquisa social: teoria, método e criatividade. 22. ed. Rio de Janeiro: Vozes, 2003. 
MINAYO, M. C. S. (Org.). Pesquisa social: teoria, método e criatividade. 21 . ed. Petrópolis: Vozes, 1994.

MIRANDA, M. J. Educação Física e saúde na escola. Estudos, Goiânia, v. 33, n.7/8, p. 643653, jul./ago. 2006

PALMA, A. Educação Física, corpo e saúde: uma reflexão sobre outros modos de olhar. Revista Brasileira de Ciências do Esporte, Campinas, v. 22, n. 2, p. 23-39, jan. 2001.

PEREGRINO, M. Uma questão de saúde: saber escolar e saber popular nas entranhas da escola. In: VALLA, V. V. (Org.). Saúde e educação. Rio de Janeiro: DP\&A, 2000. p.6I-85.

ROCHA, V. M. CENTURIÃO, C. H. Profissionais da saúde: formação, competência e responsabilidade social. In: FRAGA, A. B.; WACHS, F. Educação Física e saúde coletiva. políticas de formação e perspectivas de intervenção. Porto Alegre: Ed. da UFRGS, 2007.

SILVA, A. C. Tematizando o discurso da mídia sobre saúde com alunos do ensino médio. Motrivivência, ano 23, n. 37, p. I15-122, dez. 201 I.

SLEAP, M. Promoting health in phmary school Physical Education. In: ARMSTRONG, J. N. New directions in Physical Education. Champaign: Human Kinetics, p. 17-36, 1990. v. I

ZIMBRES, S. F. Educação Física escolar e cidadania: uma nova concepção. Revista Digital EFDeportes, Buenos Aires, ano 7, n. 38, jul. 200 I. Disponível em: <www.efdeportes.com/ efd38/cidad.htm >. Acesso em: 21 dez. 201 l. 